\title{
A New Enhanced Energy Efficient Position based Routing Protocol for Mobile Adhoc Network
}

\author{
Tanu Preet Singh, Ph.D \\ Assistant Professor \\ ACET, Amritsar \\ Punjab Technical University, Jalandhar
}

\author{
Harwant Singh Gill \\ Assistant Professor \\ GIMET, Amritsar \\ Punjab Technical University, Jalandhar
}

\begin{abstract}
Mobile Ad-hoc Network (MANET) is a combination of mobile nodes communicating and transferring data with each other to route a packet from source to their destinations. MANET is used to support dynamic routing techniques in absence of fixed wired infrastructure and centralized control. In MANET less power in mobile communication nodes is a big matter of concern. Due to this some energy efficient techniques should be implemented with existing routing protocols to increase life time of network and reduce network failure and energy. This paper is presenting an Enhanced Energy-Efficient Position Based Routing protocol. The protocol deals with various parameters as Residual Energy, Bandwidth, Load and Hop Count for route discovery. It will improve overall energy of network.
\end{abstract}

\section{Keywords}

Load, Residual energy, Bandwidth, Hop Count

\section{INTRODUCTION}

Mobile Ad Hoc Network consists of wireless mobile communicating nodes where each node acts as a router that forwards the packets from one node to another node. In MANETs every node can move freely so this uses dynamic topology. Due to this characteristics MANET is used in many today's applications. This makes routing in such networks more challenging, especially when certain Quality of Service (QoS) requirements are to be guaranteed during the routing. There is no fixed infrastructure in the MANET. While transmitting a packet from source to destination it passes through some intermediate nodes. In such a network, it may be necessary for one mobile host to enlist the other hosts in forwarding a packet to its destination, due to the limited range of each mobile host's wireless transmissions. This type of wireless network is known as mobile ad hoc network [1].

Mobile ad hoc network (MANET) is composed of a set of mobile nodes which can move anywhere freely and communicate with each other using a wireless data transfer medium .So, limited energy capacity, absence of fixed infrastructure, dynamic topology and unstable links are special features for MANET when compared to other wired networks. MANET does not have centralized controllers, which makes it different from other wireless networks [2].

MANET can be used in several areas. Some of them are: wireless mesh networks, wireless sensor network, military applications, hybrid wireless network architectures, collaborative and distributed computing, emergency operations[2].

\section{EXISTING \& RELATED WORK}

Unlike other routing protocols, our protocol uses no periodic routing overhead messages, so by reducing bandwidth of network; it uses dynamic source routing to route packets in an adhoc network. According to source routing technique the source node determines the entire sequence of nodes through which a packet has to pass from source to destination. The source node puts the list of addresses of all the intermediate nodes in the header of the packet, so that the packet is reached at destination through those specified nodes. Source routing is done using a technique called route discovery. Whenever a node want to send a packet to some other node, the sending node initiates the route discovery. Each node maintains a cache called route cache to store the information about all routes it has gathered to different destinations. To support efficient routing in energy constrained ad hoc networks, power aware routing policies can be integrated and evaluated with existing features of routing protocol [3] The routing mechanism basically involves two activities first, to find optimal routing routes and secondly, transferring data packets through network. There are various EnergyEfficient routing protocols which deal with this technique but in this paper DSR is used as base protocol. The DSR protocol is a type of reactive routing protocol for MANET. It uses source routing which means that the sender must know the complete hop-by hop route sequence to the destination node. These all routes are stored in a route cache. DSR is composed of two passes that work together to perform the route discovery and route maintenance of source routes in the ad hoc network. When a node in an adhoc network attempts to send a data packet to a destination for which it does not already know the route, it uses a route discovery mechanism to dynamically find such a route. Route discovery works by flooding the network with route request RREQ packets. Each node that receive a request rebroadcasts it, unless it is the destination or it has a route to the destination in its route cache. Such a node replies to the request with a route reply RREP packet that is routed back to the original source. Route request and reply packets are also source routed. The request builds up the path traversed so far. The routes reply itself back to the source by traversing this path backward. The route carried back by the reply packet is cached at the source for future use. If any link on a source route is broken detected by the failure of an attempted data transmission over a link, route error RERR packet is generated. Route error packet is sent back toward the sender which erases all entries in the route caches along the path that contains the broken link. A new route discovery must be initiated by the source, if this route is still needed and no alternate route is found in the cache. But sometimes an alternative path is selected from already 
available routes if source still want to interact with destination and another path should not have that error causing node. Route Maintenance is performed by each node that originates or forwards a data packet along a source route. Each such node is responsible for confirming that the packet has been received by the next hop along the source route given in the packet; the packet is retransmitted until this confirmation of receipt is received [4].

\subsection{Energy Efficient Position Based Routing Protocol}

This approach selects a route that contains nodes having maximum available residual energy so that the energy usage among all nodes can be balanced because underutilized nodes usually have more energy than utilized nodes. The approach compares not only energy but all the parameters such as bandwidth, load and hop Count for the route selection so this may result in small, best and energyrich routes for routing packets. Thus, ensures long network lifetime. [3]

In this protocol the method of broadcasting the RREQ packet for Route Discovery is same as the DSR, only the difference is in the RREQ packet format.

The intermediate node which receives the RREQ packet performs the following task:

1. It checks in its Route Cache for the availability of a route for the destination node, if it found then it attach that route in a RREP packet and sends back to the source node.

2. If the node finds its own address as actual destination, then the packet reached the final target.

3. Otherwise, that node appends its own address in that Route Record and its available residual energy in RREQ and rebroadcasts it to all its neighbor nodes.

All the routes are defined along with number of intermediate nodes from source to destination called hop count. Then minimum value of all parameters like hop count, bandwidth, residual energy and load is calculated. Then position count is calculated in final position table on the basis of next mentioned four rules. A specific route is selected having minimum value of position count. That specific route will be best suitable from all aspects like having maximum available residual energy and bandwidth etc.

The best route is selected on the basis of following rule set on the basis of minimum value of all parameters [3]:

Rule 1: If two or more than two routes have equivalent energy: Then Route with maximum available bandwidth will be accepted.

Rule 2: If two or more than two routes are of same energy and equivalent bandwidth: Then the Route having minimum Load will be considered.

Rule 3: If two or more than two routes have equivalent energy, equivalent bandwidth and equal load even then Route with minimum hop count value is considered

Rule 4: If all the available routes are not of equal energy: Then Route with maximum residual energy, maximum bandwidth, minimum load and minimum hop count should be given priority [3].

One best route having minimum value of position count is considered and all other remaining routes are taken as backup and used later on in case of failure of transmission of data packets in first best route. [6]

\section{A NEW ENHANCED ENERGY EFFICIENT POSITION BASED ROUTING PROTOCOL}

The selection of best route from all available routes is dependent upon given rule set. In enhanced energy efficient position based routing protocol while selecting a route instead of using energy first rule [3] a combination of residual energy and hop count is used. This will increase the overall energy of network and improve lifetime of network. If a route is selected according to old rule set then hop count is considered at last. A route having maximum available residual energy is selected that have hop count is not equal to minimum available hop count. When a packet will transfer from source to destination through intermediate nodes, for transmitting packet to final node in route cache energy of every intermediate will be consumed. So as the number of intermediate nodes will increase (hop count) the energy consumed for one transmission will also increased [4][5]. So it is necessary to select a route having maximum residual energy but minimum hop count .In new proposed technique while selecting a route combination of energy first rule and minimum hop count is used.

New proposed rule set is as follows:

1. If routes are of equivalent energy and equal hop count then route with maximum available bandwidth will be considered.

2. If routes are of equivalent energy, equal hop count and equal bandwidth then route with minimum load is considered.

3. If the routes are not of equivalent energy and equal hop count then route with maximum energy and minimum hop count is considered.

4. If route has equal load then select the route with maximum energy and minimum hop count.

This will save the overall energy of network. As per previous technique when a route is selected with greater hop count as compared to minimum hop count, while transmitting a packet from source to destination more energy will be consumed because every individual node will consume some energy to transmit data to next hop[3]. But when same packet will sent through a route having minimum hop count then less energy will be consumed. DSR, AODV and DSDV are compared against energy and simulation time, DSR proved better in energy efficiency. DSR is taken as basic protocol for implementing new Enhanced Energy Efficient Position Based Routing Protocol (Named as Protoname in simulation process). Simulation scenario shows energy gap between existing technique and protoname. Energy is calculated by formulae [9]:

Energy $=$ Power $*$ Time

$\mathrm{T}=($ No. of Packets *Packet size $) /$ Bandwidth

$\mathrm{TE}=\mathrm{TP} * \mathrm{~T}$ 


$$
\mathrm{RE}=\mathrm{RP} * \mathrm{~T}
$$

Where

PT: Power of Transmission, T: Time,

TP: Transmission Power, RP: Receiving Power, TE: Transmission Energy, RE: Receiving Energy

Energy consumed by a node after time interval $t$ is calculated using the equation

$\mathrm{EC}(\mathrm{T})=\mathrm{NT} * \mathrm{C} 1+\mathrm{NR} * \mathrm{C} 2$

Where, EC (T): Energy Consumed by a node after time T, NT: No. of packets transmitted by the node after time T. NR: No. of packets received by the node after time T. C1 and $\mathbf{C} 2$ are constant having a value between 0 and 1 .

Let $\mathrm{E}$ be the Initial Energy of a node and the Residual Energy (ResiE) of a node at time T, can be calculated by using the formula

$\operatorname{ResiE}=\mathrm{E}-\mathrm{EC}(\mathrm{T})$

(f)

\section{SIMULATION ENVIRONMENT}

Table 1. Simulation Setup for EEPBRP

\begin{tabular}{|l|l|}
\hline Parameter & Parameter Values \\
\hline Simulator & NS2.35 \\
\hline Antenna type & Omni directional \\
\hline Simulation Area & $500 * 400$ \\
\hline Number of Nodes & 5 \\
\hline Simulation Time & 150 Seconds \\
\hline Channel type & Wireless Channel \\
\hline $\begin{array}{l}\text { Radio propagation } \\
\text { model }\end{array}$ & $\begin{array}{l}\text { Propagation/ Two } \\
\text { Ray Ground }\end{array}$ \\
\hline
\end{tabular}

\begin{tabular}{|l|l|}
\hline MAC type & Mac/802.11 \\
\hline Interface queue type & Queue/Drop Tail \\
\hline Bandwidth & 2 Mbps \\
\hline Source type & TCP \\
\hline Traffic type & CBR \\
\hline Packet Interval & 0.05 \\
\hline $\begin{array}{l}\text { Performance } \\
\text { Parameters }\end{array}$ & $\begin{array}{l}\text { Energy, } \\
\text { Count, } \\
\text { Selection, } \\
\text { Throughput }\end{array}$ \\
\hline Transmission Power & 0.5 \\
\hline Receiving Power & 0.2 \\
\hline $\begin{array}{l}\text { Idle Power } \\
\text { Consumption (IPC) }\end{array}$ & 0.001 \\
\hline Initial Energy (E) & 10 joules \\
\hline
\end{tabular}

\section{SIMULATION RESULTS}

We have taken five mobile nodes with existing energy 10 joules. By using same simulation setup as shown in Table1 DSDV,AODV ,DSR, EEPBP and PROTONAME are simulated and find that DSR is better among from DSDV and AODV for energy efficiency (Fig4). Then DSR is compared with existing technique EEPBP and find that EEPBP is energy efficient as compared to DSR (Fig5). Then simulation result of EEPBP is compared with new technique Enhanced Energy Efficient Position Based Routing Protocol (PROTONAME) and find new technique is more energy efficient when we select a route node on the basis of combination of residual energy and minimum hop count instead of energy first rule (Fig6).

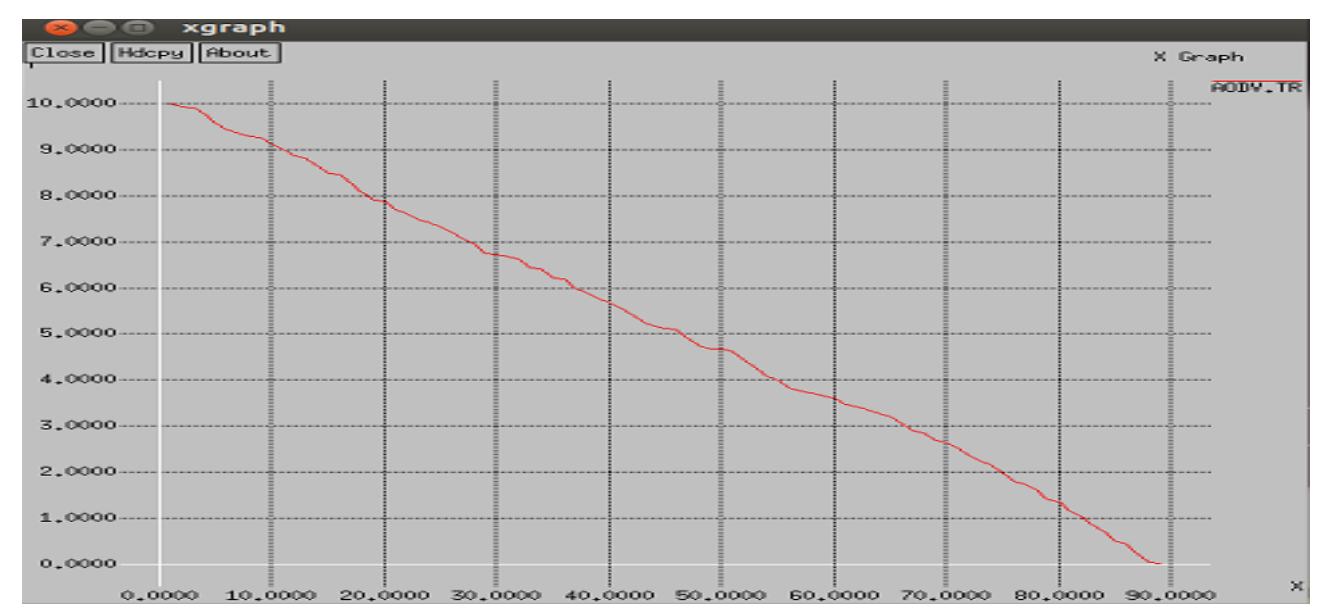

Fig1: Simulation result of AODV (Energy vs. Simulation Time) 


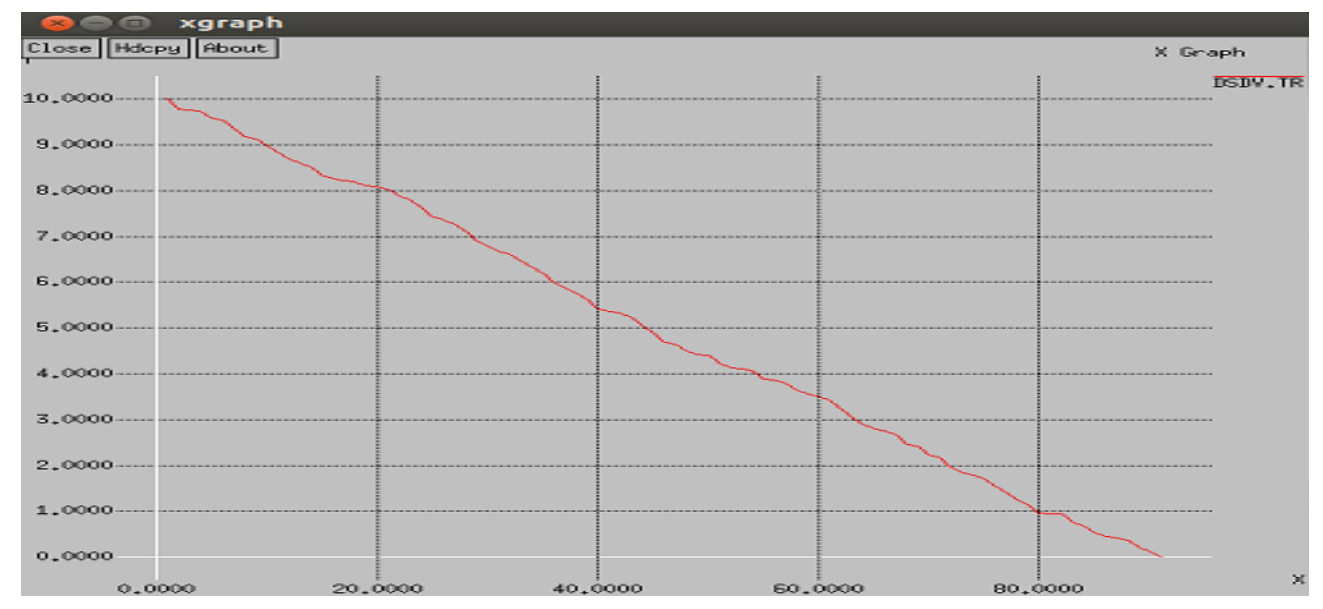

Fig2: Simulation result of DSDV (Energy vs. Simulation Time)

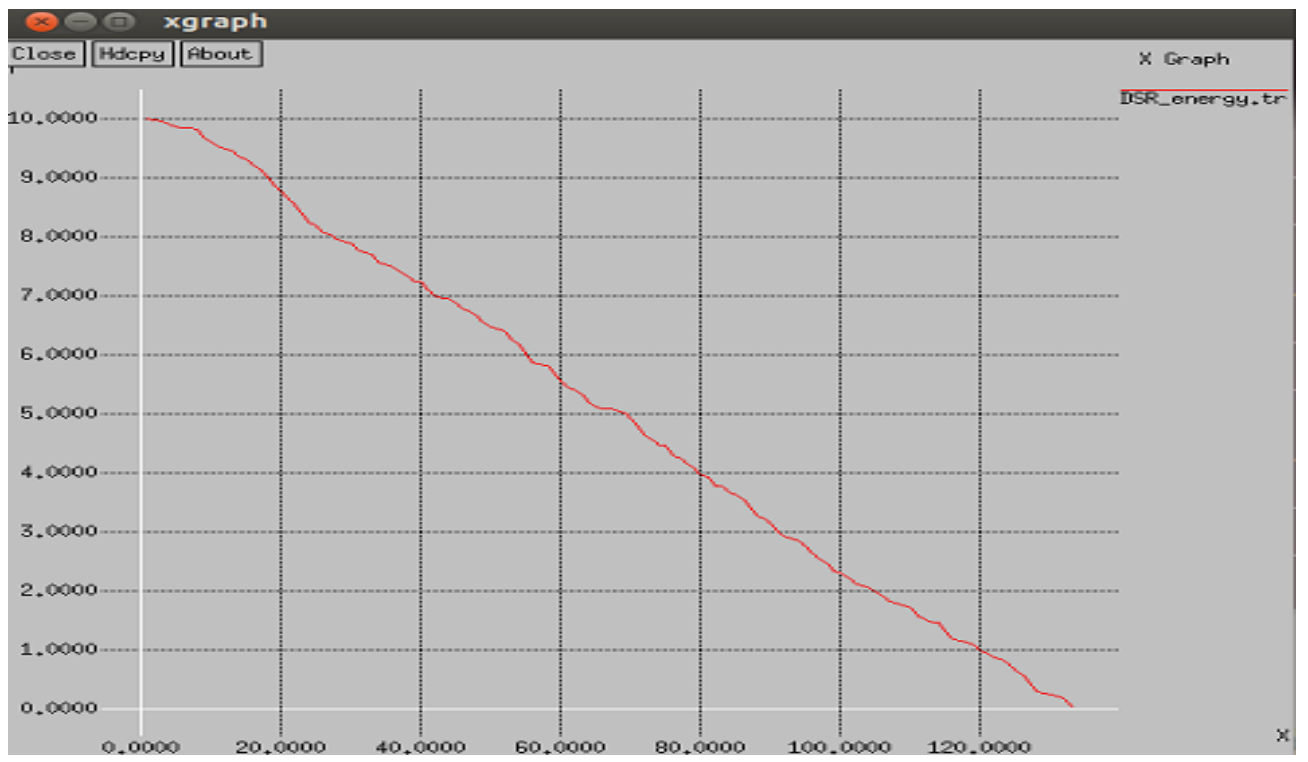

Fig3: Simulation result of DSR (Energy vs. Simulation Time)

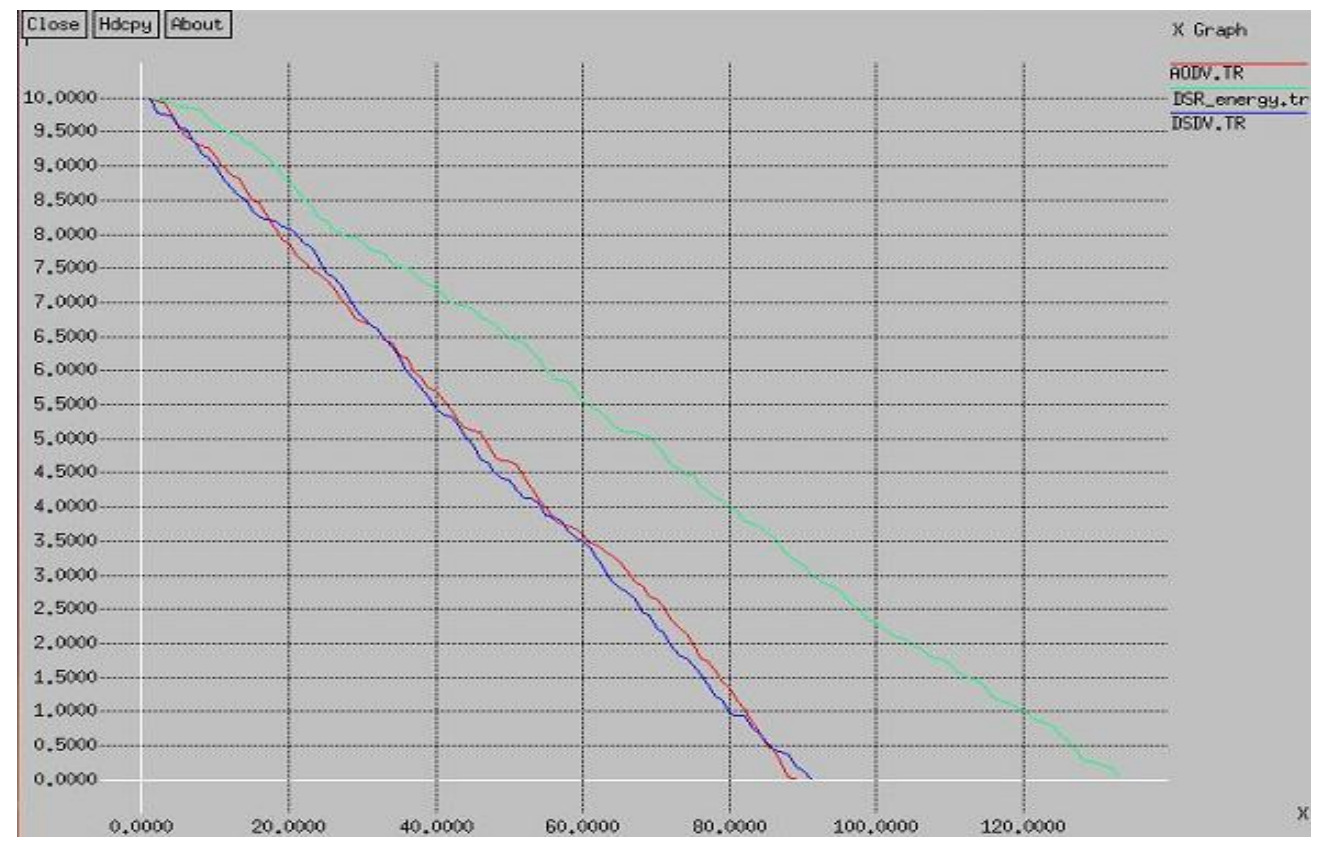

Fig4: Simulation result of DSR, DSDV and AODV (Energy vs. Simulation Time) 


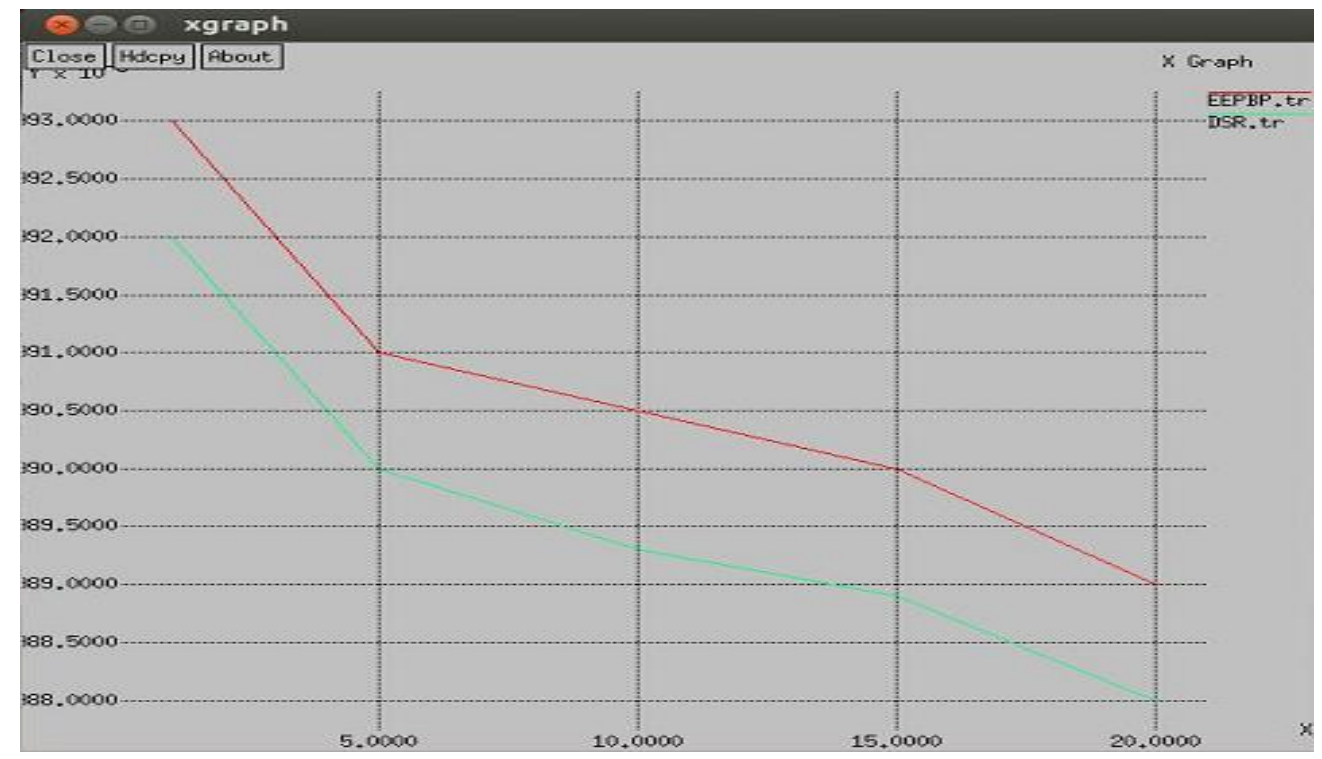

Fig5: Simulation result of DSR \& EEPBP (Energy transmitting per packet vs. Simulation Time)

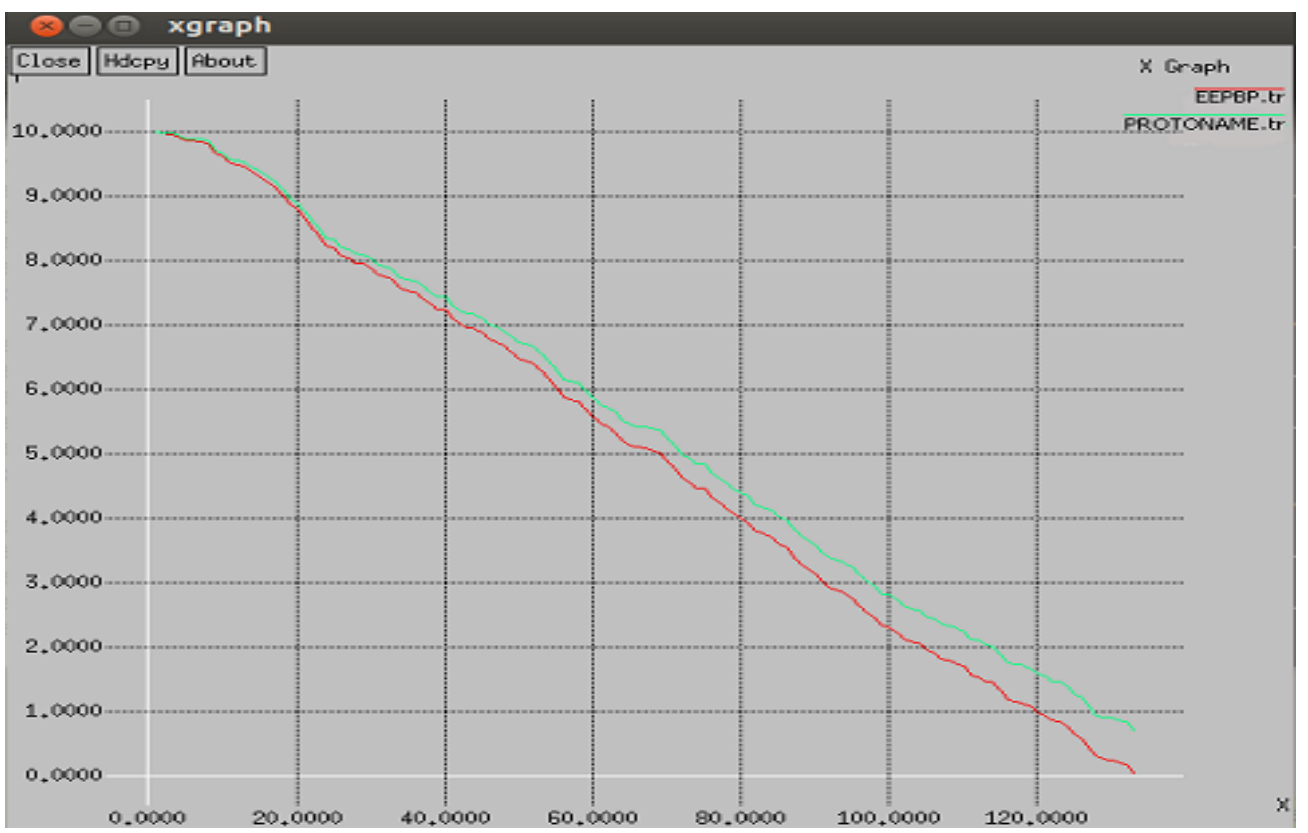

Fig6: Simulation result of EEPBP \& PROTONAME (Energy vs. Simulation Time).

\section{CONCLUSION}

In this paper, we presented an Enhanced Energy Efficient Position Based Routing Protocol (PROTONAME) for MANET with an emphasis on selecting an optimal route on the basis of combination of residual energy and hop count. If number of nodes in a route will be more, then energy consumed at each intermediate node will increase the overall energy consumption of that route. But limited battery power is also a main matter of concern in MANET. So new technique PROTONAME is helpful for selecting best route having minimum hop count, maximum residual, minimum load and maximum bandwidth and this increase the overall energy of network. Due to any reason if that selected optimal route stop transferring data then another alternative route is selected from final route table that is without sinking node if sender still want to communicate with destination. If not a such route is available in final route table then again RREQ packet is transmitted to all neighbor nodes as mentioned previously that find all routes to transmit data from source to destination.

\section{REFERENCES}

[1] Makul Mahajan, Tanu Preet Singh "Comparative Analysis of AODV, DSDV and DSR Protocol by Varying Pause Time in MANET", National Conference, LDSEM-2014.

[2] C. Siva Ram Murthy, B. S. Manoj, "Ad Hoc Wireless Networks Architecture and Protocols", $2^{\text {nd }}$ Edition, Pearson Education, 2005.

[3] Supriya Srivastava, A.K. Daniel, R. Singh and J.P. Saini "Energy-Efficient Position Based Routing Protocol for Mobile Ad Hoc Networks" IEEE 2012

[4] P. Sivasankar, C. Chellappan, S. Balaji "Optimised Energy Efficient Routing Protocols and their Performance Comparison for MANET" 
[5] Bor rong chen and C.Hwa Chang. Mobility impact on adhoc networks, IEEE 2003 proceedings

[6] Sonam Jain, Sandeep Sahu "Topology vs Position based Routing Protocols in Mobile Ad hoc Networks: A Survey", IJERT 2012.

[7] P. Sivasankar, C. Chellappan, S. Balaji "Optimised Energy Efficient Routing Protocols and their Performance Comparison for MANET" EJSR 2012

[8] N.Kumar, Dr.C.Suresh Gnana Dhass,"A Complete Study on Energy Efficient Routing Protocols DSR, ZRP and DSDV In Mobile Ad Hoc Networks", IJES 2012

[9] Shivashankar, Varaprasad., Suresh H, Devaraju , Jayanthi. 'Performance Metrics Evaluation of Routing Protocols in MANET", IJARCCE 2013

[10] A. Khetrapal,"Routing techniques for Mobile AdHoc Networks Classification and Qualitative/Quantitative Analysis", CSREA 2006 Delhi University.

[11] Samyak Shah, Amit Khandre, Mahesh Shirole and Girish Bhole, "Performance Evaluation of Ad Hoc Routing Protocols Using NS2 Simulation". CoMPC 2008

[12] Robinpreet Kaur \& Mritunjay K. Rai, "A Novel Review on Routing Protocols in MANET", Undergraduate Academic Research Journal, ISSN: 2278-1129, Vol1, Issue 1, 2012

[13] Geethu Mohandas, Dr.Salaja Silas, Shini Sam, "Survey on Routing Protocols in Mobile Ad Hoc Network", IEEE 2013.

[14] Li Yuanzhou, Hu Weihua, "Optimization Strategy for Mobile Ad Hoc Network Based on AODV Routing Protocol", IEEE 2010

[15] E.M Belding-Royer, C.-K Toh, "A review of current routing protocols for ad-hoc mobile wireless networks", IEEE Personal Communications Magazine (April 1999) 46-55.

[16] Ammar Odeh, Eman AbdelFattah and Muneer Alshowkan, "Performance Evaluation Of AODV And DSR Routing Protocols In Manet Networks", International Journal of Distributed and Parallel Systems (IJDPS) Vol.3, No.4, July 2012.

[17] G.Vijaya Kumar ， Y.Vasudeva Reddyr ， Dr.M.Nagendra , "Current Research Work on Routing Protocols for MANET: A Literature Survey", International Journal on Computer Science and Engineering Vol. 02, No. 03, 2010, 706-713

[18] NS-2, The ns Manual (formally known as NS Documentation) available at http: //www.isi.edu/nsnam/ns/doc

[19] Doina Bein , Ajoy K. Datta, Prathima Sajja, and S.Q. Zheng, "Impact of Variable Transmission Range in All-Wireless Networks", Proceedings of the 42nd Hawaii International Conference on System Sciences, 2009

[20] Sunil Tanejaa, Ashwani Kushb, Amandeep Makkarc, and Bharat Bhushand, "Power Management in Mobile Adhoc Network" International Transaction Journal of Engineering, Management, \& Applied Sciences \& Technologies, Vol. 2, No. 2, pp.45-53, 2011.

[21] Dr. R.K. Chauhan, Ashish Chopra, “Energy Efficient Routing in Mobile Ad Hoc network with Capacity Maximization", IJCA Special Issue on Mobile Ad-hoc Networks MANETs, 2010

[22] Shivashankar, Varaprasad.G, "Study of Routing Protocols for Minimizing Energy Consumption Using Minimum Hop Strategy in MANETS", International Journal of Computing communication and Network Research, Vol. 1, No. 3, pp. 10-21, 2012. 